\title{
Есть мнение. Деление оптометрии на кабинеты простой и сложной коррекции - рационально ли?
}

\author{
Деревянченко Александр И., \\ врач-офтальмолог, директор оптических \\ сетей «Мир оптики» и «Арт оптика», \\ г. Волгоград
}

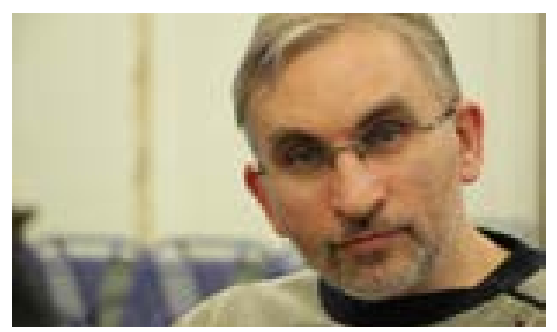

Для обсуждения вопроса работы оптометристов, на мой взгляд, прежде всего надо понимать, что мы хотим - т. е. провести анализ дел, на его основе определить текущие и стратегические цели, а также методы их достижения. Отсутствие единства в этих вопросах создает недопонимание и противоречивость мнений.

\section{Анализ дел:}

1. Рефракционные нарушения нарастают среди популяции и будут расти далее до охвата 90-95\% населения во всех возрастных группах. Рефракционные нарушения молодеют, увеличивается доля детей до 7 лет. Возраст после 35-40 лет требует прогрессивной очковой коррекции для сохранения физиологического зрения как процесса здоровья глаз. Кроме этого возник новый тип рефракционных нарушений - индуцированные, возникающие вследствие рефракционной хирургии, и требующие другого, более сложного подхода к коррекции. Сложившаяся ситуация не может обеспечить качественное оказание услуг пациентам с рефракционными нарушениями в государственной системе здравоохранения.

Необходимо сделать доступной профессиональную оптометрическую помощь.

2. Для снижения инвалидности по зрению, особенно у лиц трудоспособного возраста и детей, требуется правильная, полная и эффективная коррекция. Дети и молодежь не готовы носить очки, но готовы использовать контактные линзы. Продвижение контактных линз как эффективного и безопасного метода коррекции - это обеспечение достойного качества жизни этих детей в будущем и защита населения от инвалидности по зрению.

Необходимо дать возможность населению правильно использовать контактные линзы под контролем профессионалов, а не самостоятельно.

3. Оптометрия и офтальмология - это не одно и то же. За последнее годы значительно повысился профессионализм оптометристов в России (появились специализированные колледжи и курсы, выпускающие специалистов со средним специальным образованием), а врачи больше ориентированы на вопросы офтальмологии и меньше и, главное, хуже разбираются в оптометрии. Фактически, в настоящее время именно оптометристы ведут основную работу и по очковой, и по контактной коррекции зрения.
Необходимо рационально использовать профессиональные ресурсы, так как офтальмологов не хватает и в самой офтальмологии, и тем более в оптометрии. Делать акцент на офтальмологов в оптометрии неверно ни по профессиональной подготовке, ни по количеству доступных врачей.

4. Несмотря на улучшение оптометрической деятельности, некоторые вопросы остались открытыми. Для их решения лучше создать и внедрить новую профессию - врача-оптометриста, ориентированного на сложные оптометрические задачи: подбор жестких контактных линз, ортокератологических и склеральных линз, индивидуальных контактных линз и пр. Но это перспектива.

Исходя из вышесказанного, появляются следующие цели:

1. Создать ясную правовую конструкцию, отражающую текущее состояние организации оптометрии на основании сложившихся технологий, опыта и отвечающую задачам текущего периода.

2. Нормативные документы должны быть согласованы с вопросами лицензирования и быть ясными, четкими, исключать двусмысленные трактовки для недопущения коррупции в данной сфере.

3. Повысить доступность оптометрической помощи для населения и прежде всего в области контактной коррекции зрения.

4. Правильно и рационально использовать профессиональные ресурсы с учетом интересов и оптометрии, и офтальмологии в целом в России.

\section{Предложенные решения, их анализ}

Фактически предложенная конструкция - простой и сложный кабинет оптометрии - не решает ни одну из нужных целей.

1. Ограничение работы по подбору контактных линз в кабинете простой коррекции снижает доступность профессиональной помощи по их подбору, и, следовательно, направляет пациентов на бесконтрольное использование контактных линз, приобретение их в интернете или в вендинговых автоматах. 
2. Выделение врача как лучшего специалиста по оптометрии не является верным, так как большинство врачей не имеют специальной подготовки по оптометрии, в отличие от оптометристов, знающих современную оптометрию ЛуЧШЕ врачей!

3. Предложенная конструкция - объединить оптометриста и врача в кабинете сложной коррекции, не согласуется с вопросами лицензирования, так как медицинская оптика - это лицензия среднего персонала, и она самостоятельна; офтальмология - лицензия высшего образования, и она также самостоятельна. Более того, это создает неясность, почему возникла разница в компетенции работы оптометриста в простом кабинете и в сложном при одном и том же уровне образования.

4. Предложенные варианты фактически нерационально используют профессиональные ресурсы в России, что в итоге приведет к ухудшению работы и в оптометрии, и в офтальмологии.

\section{Новые предложения:}

\section{Кабинет простой оптометрии:}

- лицензия - медицинская оптика;

- квалификация - оптометрист со средним образованием;

- компетенция - все виды очковой коррекции; контактные линзы серийного производства; выполнение лечебных действий с использованием аппаратных методов лечения в оптометрии; работа с населением по выявлению заболеваний глаза, его придаточного аппарата и орбиты и направление их в офтальмологические кабинеты; санитарно-просветительная работа по оптометрии и офтальмологии; участие в выполнении программ, направленных на профилактику слепоты и слабовидения; представление отчетности по видам, формам, в сроки и в объеме, которые установлены уполномоченным федеральным органом исполнительной власти, сбор и представление первичных данных о медицинской деятельности для информационных систем в сфере здравоохранения;
- возраст пациентов с 7 лет, если хотя бы однократно было обследование врача-офтальмолога.

Кабинет сложной и специальной коррекции зрения:

- лицензия - офтальмология;

- квалификация - врач-офтальмолог, высшее образование;

- компетенция - все виды очковой коррекции; контактные линзы серийного производства; жесткие контактные линзы; ортокератологические и индивидуальные контактные линзы; оказание первичной специализированной медико-санитарной помощи, специализированной медицинской помощи взрослому населению при заболеваниях глаза, его придаточного аппарата и орбиты, включающей консультативно-диагностические, лечебные и реабилитационные мероприятия пациентам, нуждающимся в коррекции зрения в амбулаторных условиях; участие в выполнении программ, направленных на профилактику слепоты и слабовидения; представление отчетности по видам, формам, в сроки и в объеме, которые установлены уполномоченным федеральным органом исполнительной власти, сбор и представление первичных данных о медицинской деятельности для информационных систем в сфере здравоохранения;

- возраст пациентов - любой.

HO, необходимо признать, что работа по подбору жестких, ортокератологических и индивидуальных контактных линз требует специальной подготовки, и врачи-офтальмологи в настоящее время не все обладают такой компетенцией. В связи с этим требуется разработка и внедрение новой профессии врач-оптометрист, а до его появления оставить данные вопросы в сфере работы врача-офтальмолога, понимая, что врач в этом случае должен иметь дополнительные компетенции.

Все указанные вопросы обсуждались на этапе принятия новых стандартов кабинетов оптометрии, но не были учтены в итоговом решении.

Om редакции. Несмотря на то, что Приказ Министерства здравоохранения РФ от 9 июня 2020 г. N 558 н «О внесении изменений в Порядок оказания медицинской помощи взрослому населению при заболеваниях глаза, его придаточного аппарата и орбиты, утвержденный приказом Министерства здравоохранения Российской Федерации от 12 ноября 2012 г. N 902 н» уже вышел (подробнее читайте в разделе Медицина и закон), Редакция считает, что вносить поправки в любой закон можно и нужно, и никогда не поздно. Все зависит от нас с вами. Поэтому мы приглашаем всех принять самое активное участие в обсуждении. Ждем ваши замечания и предложения! 